\title{
The phenomenal determination of retroaction and proaction: II. Evidence for interference during the simultaneous acquisition of two lists
}

\author{
LEONARD BROSGOLE and FRANK X. DUFFY \\ St. John's University, Jamaica, New York 11439
}

\begin{abstract}
In the first study, subjects learned two lists simultaneously by alternating between them from trial to trial. They would reach criterion on one list before the other, but the task ended only when criterion was achieved on both. The recall of the two lists was assessed $10 \mathrm{~min}$ and $24 \mathrm{~h}$ after the completion of original learning. It was found that the short-term recall of the first list learned (the "prior" one) was inferior to the second list learned (the "recent" one), but the two equalized by $24 \mathrm{~h}$. The equalization occurred as the recall of recent list deteriorated. A second experiment showed that this effect occurred only when the two lists were similar. We concluded that retroaction and proaction are produced when two similar tasks are organized sequentially, even though acquired simultaneously.
\end{abstract}

In the standard retroaction design, original learning is followed by a period of interpolated activity. According to two-factor theory, the interpolated session leads to the extinction of original learning, resulting in retroaction. However, the originally learned responses spontaneously recover with the passage of time and come to compete with the interpolated responses. This allegedly results in proaction.

In a series of earlier papers, Brosgole (1976a, b) and Brosgole, Lederer, and Kozlowski (1976) argued that extincton may not be needed to produce retroaction and proaction. It is entirely possible that interpolation merely allows the learned materials to be organized in memory, i.e., in terms of "this preceded that." It was contended that such perceptual "primacy-recency" may lead to retroaction and proaction in the absence of interpolated activity.

In the typical design, the original task is perceived as coming first, because it is both presented and mastered prior to interpolation. In the present study, subjects were presented with two tasks, namely, two serial lists that had to be mastered to a partial criterion. Instead of following one with the other, however, the subjects were required to alternate between the two from trial to trial and attempt to learn them at an equal rate. Obviously, the subjects would tend to forge ahead on one list, then have to catch up on the other. Thus, they would reach criterion on one list before the other, thereby establishing a condition of primacy-recency during the simultaneous learning of two tasks. It was speculated that retroaction would be observed in the recall of the "prior" list and proaction in the phenomenally "recent" list.

\section{EXPERIMENT I}

\section{Method}

Subjects. Sixteen males and eight females participated in this study. Ranging in age from 19 to 30 years, their mean age was 25.2 years. All were naive as to the purpose of this experiment.
Apparatus and materials. Two serial lists were constructed. Each consisted of 16 CVC trigrams of $0 \%$ association value, according to the Glaze table. The syllables were fixed in order and appeared in bold black type. Both lists were typed on the same sheet of paper, one on the left and the other on the right. The one to the left was clearly labeled "List 1 " and the one to the right, "List 2." The lists were displayed on a Stoelting memory drum (Model KYC 23RB). The drum was equipped with an aperture that could slide from side to side, thereby allowing the alternate presentation of lists.

Procedure. The subjects learned both lists by the method of anticipation. First they saw the list on the left, then the one on the right, then back to the one on the left, and so on, until they reached a criterion of 8 out of 16 correct to each list. As previously noted, the subjects tended to reach criterion on one list prior to the other. Sometimes it was the one on the left and other times the one on the right. In any event, that list was designated as the "prior" list. The alternation procedure continued as the subjects were catching up on the "recent" list. If a subject went above criterion on the prior list while catching up on the recent one, that subject was immediately dropped from the procedure. Thus, the same criterion level was obtained to the prior and recent lists, with both exposed an equal number of times. The dual control over both acquisition level and trials to criterion is rarely, if ever, achieved in the standard design. The syllables were exposed at a 2 -sec rate during learning, with no delay between items. There was a 10 -sec interval between the completion of one list and the start of the next.

Half the subjects (Group 1) were retested on the "prior" list $10 \mathrm{~min}$ after reaching criterion. The remaining half (Group 2) were tested on the recall of the "recent" list. The method of anticipation was used in both instances. Recall was again ascertained $24 \mathrm{~h}$ later for both groups. A subterfuge was used in an attempt to preclude rehearsal during the 24-h interval.

\section{Results and Discussion}

In the $10-\mathrm{min}$ test, a mean of 5.25 items were recalled from the prior list, compared to 6.67 from the recent list. Recall of the prior material increased to a mean of 5.58 correct after $24 \mathrm{~h}$, while recall of the recent items decreased to 4.25 . These data were subjected to a 2 by 2 split-plot factorial design with one within-subject (Time) and one between-subject (Lists) factor.

There was a significant two-way interaction $(F=11.64, \quad d f=1 / 22, p<.01)$. Subsequent simple 
effects indicated that, while significantly more recent items were recalled after $10 \mathrm{~min}(F=6.3, \mathrm{df}=1 / 44$, $\mathrm{p}<.05)$, significantly more prior items were remembered after $24 \mathrm{~h}(\mathrm{~F}=5.58, \mathrm{df}=1 / 44, \mathrm{p}<.05)$. In addition, while there was no substantive change in the recall of the prior items with time, the recent material deteriorated reliably $(\mathrm{F}=17.97, \mathrm{df}=1 / 22, \mathrm{p}<.01)$. The initial superiority in the recall of the recent material can be interpreted as retroaction, and its deterioration with time can be construed as proaction. This is bolstered by an analysis of the frequency data within each group.

While 8 of 12 subjects improved in their recall of the prior list with time, only 1 of 12 improved in the recall of the recent list. The two distributions differed significantly according to the Fisher test $(p<.01)$. Accordingly, it may be concluded that the prior material spontaneously recovered from retroaction to proactively interfere with the recent list.

It may be argued that retroaction and proaction cannot be inferred from an interaction of Lists by Time. Rather, they should be defined with reference to a control, and there was no control group run. It would seem that the legitimacy of comparing a standard control to a group involved in simultaneous learning is questionable. It was reasoned, however, that if retroaction and proaction were being observed, then the above effects should vary as a function of the similarity between lists. Accordingly, these groups were created in the following study. While Group 1 simultaneously learned two highly similar lists, Group 2 learned moderately similar lists and Group 3 learned two neutral lists.

\section{EXPERIMENT II}

\section{Method}

Subjects. Sixteen males and 14 females participated in this study. Ranging in age from 18 to 30 years, their mean age was 21.7 years. All were naive as to the purpose of the experiment.

Groups. As noted above, three groups were created; each group contained 10 subjects. Just as before, every subject had to learn two lists simultaneously. Unlike the last study, however, each person was tested for the recall of both lists at $10 \mathrm{~min}$ and $24 \mathrm{~h}$. Thus, the lists became a within-subject factor.

Apparatus and materials. A standard list was constructed. It consisted of a fixed series of 12 CVC trigrams which appeared in bold black type and were of $0 \%-20 \%$ association value according to the Glaze table. The list was carefully balanced to minimize intraserial interference. No two syllables began or ended with the same consonant, and no vowel was used more than three times. For Group 1, a highly similar list of trigrams was matched to the standard list. Four syllables in the two lists began with the same consonant and vowel, four ended with the same vowel and consonant, and four had the same consonants but different vowels. For Group 2, the lists were moderately similar in that no two syllables shared more than one letter in common. Thus, similarity was reduced virtually to that of form class alone. Finally, the lists were neutral in Group 3, where the standard was matched with a list of randomly selected two-digit numbers.

The two lists in each group were mounted on separate Lafayette Instrument memory drums (Model 303). The serial lists appeared on the drums in four different orders, with the order varied from trial to trial. The standard list was presented on the drum to the left for half the subjects and on the right for the remaining half. The list on the left was always designated as List 1 and the one on the right as List 2.

Procedure. The subjects alternated between lists, just as before. However, this time they had to pronounce each item aloud as it appeared in the drum. The items were exposed at a 2 -sec rate, with no interstimulus interval. A written test of free recall followed each complete exposure of the list. There was no time limit placed upon the test, and there was no requirement to remember the items in their proper order. The trials continued until the subjects met a dual criterion of six to eight correct on each list.

A written test of modified free recall was given 10 min after completion of original learning. The subjects were required to write down everything they could remember from both lists, with no time restriction. They did not have to identify the list from which each item came. The test was administered again $24 \mathrm{~h}$ later. A subterfuge was used in an attempt to preclude rehearsal during the 24-h delay interval.

\section{Results and Discussion}

The criterion level for original learning was not as rigid as in the first study. This time the subjects were permitted to get six to eight correct on the last trial to each list. The flexible criterion was adopted to prevent an abundant loss of subjects. In fact, only three subjects were dropped, and those were in Group 3, where it was apparently easier to learn the two-digit numbers than the syllables. Because of the variation now permitted in criterion level, the last trial performance was included in the analysis. Thus, there were three recall periods to the prior and recent lists: immediate (last trial), 10-min, and 24-h recall. This enabled us to ascertain whether there was any forgetting relative to criterion level. Lists (prior and recent) and Time of Recall were both withinsubject factors, while Groups (reflecting the degree of similarity between lists) was a between-subject factor. The data were transformed (using $\sqrt{\mathrm{X}+.5}$ ) and subjected to a split-plot factorial design. There was a significant three-way interaction $(F=5.68, d f=4 / 54$, $\mathrm{p}<.01$ ), indicating that the groups differentially recalled the lists as a function of time. These differences were further explored using simple-simple effects.

Group 1 (highly similar) reached criterion on the prior list with a mean of 6.7 items correct, compared to 5.2 correct $10 \mathrm{~min}$ later and 4.9 after $24 \mathrm{~h}$. There was a significant decrement in the recall of the prior list with time $(F=9.55, \quad d f=2 / 108, \quad p<.01)$. Subsequent Newman-Keuls indicated that the only significant deterioration was from original learning to the 10 -min retest $(p<.01)$, with no change thereafter. The recent list changed with time as well, from a mean of 6.8 correct at criterion to $6.710 \mathrm{~min}$ later and 5.7 after $24 \mathrm{~h}$ $(\mathrm{F}=4.10, \mathrm{df}=2 / 108, \mathrm{p}<.05)$. However, the drop occurred between $10 \mathrm{~min}$ and $24 \mathrm{~h}$ in this instance $(p<.05)$. These data indicate that the phenomenally prior list was affected by retroaction and the recent list by proaction, which is attested to further by the fact that there was significantly greater recall of the recent 
list at $10 \min (F=8.19, \mathrm{df}=1 / 81, \mathrm{p}<.01)$. There was no difference after $24 \mathrm{~h}$.

The same applied to the second (similar) group. On the last trial of original learning to the prior list, this group got a mean of 6.8 correct, compared to 4.6 and $4.710 \mathrm{~min}$ and $24 \mathrm{~h}$ later. Again there was a significant drop in recall with time $(\mathrm{F}=16.44, \mathrm{df}=2 / 108, \mathrm{p}<.01)$, with the decrement occurring between the last trial of original learning and the $10-\mathrm{min}$ retest $(\mathrm{p}<.01)$. There was a mean of 6.7 correct on the last trial to the recent list, with 6.7 correct $10 \mathrm{~min}$ later and 4.9 after $24 \mathrm{~h}$. These changes were also significant $(F=11.15$, df $2 / 108$, $\mathrm{p}<.01$ ), but the only drop was between $10 \mathrm{~min}$ and $24 \mathrm{~h}(\mathrm{p}<.01)$. Thus, once again there was a deficit in the short-term recall of the prior list, accompanied by a long-term deterioration in the recent list. As before, a comparison of lists indicated that there was significantly better recall of the recent list at $10 \mathrm{~min}(\mathrm{~F}=18.64$, $\mathrm{df}=1 / 81, \mathrm{p}<.01$ ), with no difference between the lists after $24 \mathrm{~h}$.

The third (neutral) group was entirely different than the other two. Here, there was a mean of 7.0 items correct to the prior list at criterion, compared to 6.8 and 6.1 at the 10-min and 24-h tests, respectively. The simple-simple effects revealed that there was no substantive change in the recall of the prior list with time. Only the recent list changed, as there were 6.4 items correct at criterion and 5.1 after both $10 \mathrm{~min}$ and $24 \mathrm{~h}$ $(\mathrm{F}=5.83, \mathrm{df}=2 / 108, \mathrm{p}<.01)$. The drop that occurred was obviously between original learning and the 10-min test $(p<.01)$. A comparison of lists for this group indicated that they were different at the 10 -min test only $(F=10.83, \mathrm{df}=1 / 81, \mathrm{p}<.01)$, where there was significantly greater recall of the prior list.

A comparison across groups indicated that they differed at $10 \mathrm{~min}$ only with regard to both the prior $(\mathrm{F}=7.05, \mathrm{df}=2 / 162, \mathrm{p}<.01)$ and recent $(\mathrm{F}=4.55$, $\mathrm{df}=2 / 162, \mathrm{p}<.05)$ lists. Group 3 recalled significantly more items to the prior list than the other two groups
( $p<.05$ in each instance), which in turn did not differ from each other. With respect to the recent list, Group 3 recalled significantly fewer items than the others ( $p<.05$ in each case). Groups 1 and 2 did not differ. Using Group 3 as a control, then, we can see that the introduction of similarity had the effect of placing a phenomenally prior list at a decided disadvantage in short-term recall. To the contrary, the cognitively recent material was at a marked advantage. Thus, the phenomenal organization of primacy-recency was sufficient to generate retroaction and proaction, as defined by either a statistical interaction of Lists by Time or with reference to a control.

One further note is worthy of comment. Variations in formal similarity had little effect upon the data, as witnessed by the fact that Groups 1 and 2 did not differ significantly. It may be noted, however, that Group 1 did not suffer from as much retroaction and proaction as Group 2. Group 1 recalled a mean of .6 more items to the prior list at the 10 -min test and .8 more items to the recent list after $24 \mathrm{~h}$. Although these differences were not significant, they point in the right direction. That is to say, we observed the emergence of a facilitation effect with increases in list similarity. All of the above support the basic premise that retroaction and proaction are phenomenally determined.

\section{REFERENCES}

Brosgole, L. Associative symmetry: V. An interference interpretation of the failure of stimulus availability. Bulletin of the Psychonomic Society, 1976, 7, 177-178. (a)

Brosgole, L. Phenomenal determination of retroactive and proactive interference. Psychological Reports, 1976, in press. (b)

Brosgole, L., Lederer, W. G., \& Kozlowski, K. D. The phenomenal determination of retroaction and proaction: I. Interference within pairs of a single list. Bulletin of the Psychonomic Society, 1976, in press.

(Received for publication May 20, 1976.) 